Retros

\title{
Disorders of follicle development and steroidogenesis in ovaries of androgenised foetal sheep
}

\author{
Fabio V Comim ${ }^{*}{ }^{+}$, Kate Hardy ${ }^{*}$, Jane Robinson ${ }^{1}$ and Stephen Franks \\ Imperial College London, Institute of Reproductive and Developmental Biology, London W12 0NN, UK \\ ${ }^{1}$ Institute of Biodiversity, Animal Health and Comparative Medicine, University of Glasgow, Glasgow G61 1QH, UK \\ * (F V Comim and K Hardy contributed equally to this work) \\ ${ }^{\dagger} \mathrm{F} V$ Comim is now at the Department of Clinical Medicine of the Federal University of Santa Maria, UFSM, \\ Santa Maria, Brazil
}

Correspondence should be addressed to S Franks

Email

s.franks@imperial.ac.uk

\begin{abstract}
The prenatally androgenised (PA) sheep is a well-recognised model for the study of developmental programming of adult polycystic ovary syndrome (PCOS). Most of the studies to date have involved examination of the reproductive and metabolic effects in the offspring after puberty, but more recently, it has been reported that there is disruption of follicle formation and steroid gene expression in ovaries of foetal sheep after exposure of the mother to excess androgen. Our study examines evidence for precocious primordial follicle formation at day 90 of gestation in ovaries of foetal Poll Dorset sheep. Using a specific marker of germ cells (VASA homologue protein) in ovarian sections, we found that androgenised sheep had nearly double the proportion of germ cells enclosed in follicles compared with control animals. When analysed by follicle stage, there was no significant difference between groups in the proportion of primordial follicles and growing (transitional and primary) follicles. Differences between PA and control foetal sheep were found in both mRNA and in protein expression of steroidogenic enzymes and androgen receptor. Our results in Dorset ewes are complementary to previous reports, but suggest that the timing of follicle formation and steroidogenic activity may vary between different breeds as well as in response to androgen. These data show that granulosa cells constitute a specific target for programming by androgen in utero and raise key questions about the role of exposure to androgen in utero in developmental origins of PCOS.
\end{abstract}

\section{Key Words}

- follicular development

- prenatal androgenisation

- PCOS

- VASA

\section{Introduction}

Polycystic ovary syndrome (PCOS) is the most common endocrine disorder in women, affecting $5-10 \%$ of females of reproductive age (Franks 1995, Diamanti-Kandarakis et al. 1999). PCOS is clinically evident at puberty, but emerging data from suitable animal models suggest that exposure to excess androgen during critical periods of gestation can programme the appearance of PCOS traits in adulthood
(Abbott et al. 2002, Padmanabhan \& Veiga-Lopez 2011, 2012). In one of these models, the prenatally androgenised (PA) sheep, animals are exposed during gestation to high doses of testosterone, administered to their mothers (Sharma et al. 2002, Forsdike et al. 2007, Padmanabhan \& Veiga-Lopez $2011,2013)$. Prenatal testosterone excess leads to reproductive and metabolic abnormalities in offspring during puberty

Published by Bioscientifica Ltd. 
and beyond that closely resemble those observed in PCOS. More recently, similar experimental protocols have been employed to assess the impact of androgens (whether given to the mother or directly to the foetus) on foetal ovarian function (Smith et al. 2009, Hogg et al. 2011).

The purpose of our study was to investigate, in foetal Poll Dorset sheep, whether prenatal androgenisation affects the formation of primordial follicles in the ovary at day 90 of gestation, a time when there is active (but incomplete) follicle formation. By means of immunohistochemistry (IHC) for a specific marker of germ cells (VASA protein), it was possible to establish the proportions of germ cells that were enclosed by pre-granulosa (somatic) cells to form primordial follicles. We also wished to examine the effect of androgen exposure on activation of follicle growth (i.e., recruitment of follicles into the growing pool). As an important adjunct to the study of follicle dynamics, we investigated the effects of androgen on foetal ovarian steroidogenesis by measuring the expression of mRNA and protein for androgen receptor (AR) and key steroidogenic enzymes in the androgen biosynthetic pathway.

\section{Materials and methods}

\section{Animals}

Overall, 12 of 25 female Poll Dorset sheep received injections of testosterone propionate $(100 \mathrm{mg}$ i.m. biweekly) from day 30 to 90 of gestation in the second breeding season, as previously described (Forsdike et al. 2007). Gestation was interrupted and ovary samples from 12 foetuses (six androgenised; six control) were obtained at day 90. Samples for IHC and gene expression were obtained from the same or contralateral ovary. This study was carried out under Home Office (UK) Project licences number 80/1037 and 80/1506.

\section{Immunohistochemistry}

Ovaries were removed from foetal sheep at day 90 of gestational life and sections prepared for IHC by methods well established in our laboratory (Stubbs et al. 2005, 2007). Briefly, slides were dewaxed and rehydrated through an alcohol series. Antigen was retrieved with citrate buffer $(0.01 \mathrm{~mol} / \mathrm{l}, \mathrm{pH} 6$, boiling for $20 \mathrm{~min})$, and exogenous peroxidases were blocked with $0.3 \%$ hydrogen peroxide in methanol $(30 \mathrm{~min})$. Nonspecific antibodybinding was reduced by $20 \mathrm{~min}$ incubation with $10 \%$ (vol/vol) normal goat serum in PBS (Invitrogen Life Technologies) supplemented with $4 \%$ (wt/vol) BSA
(Sigma-Aldrich). The sections were labelled using the following antibodies: AR (RDI-andracept abr, RDI Fitzgerald Industries, Concord, NH, USA), CYP17A1 (P450c17; from Dr Richard Parker Jr, University of Alabama at Birmingham, USA), HSD3B2 (3BHSDII; from Dr JI Mason, Edinburgh University) and VASA homologue antibody (from Dr T Noce, Mitsubishi Kagaku Institute from Life Sciences, Japan). Apart from the VASA antibody, which was used without dilution, optimal concentrations of antibodies were determined (after the setup of antibody dilution curves in PBS with $20 \%$ goat serum) to be respectively $1: 1600$ for $A R, 1: 40$ for CYP17A1 and 1:200 for HSD3B2. All primary antibodies were incubated overnight at $4{ }^{\circ} \mathrm{C}$. The sections were subsequently incubated with secondary antibodies: goat anti-mouse (BA9200, Vector, Peterborough, UK) for VASA and CYP17A1 and goat anti-rabbit (E0432, DAKO, Glostrup, Denmark) for the other proteins. The expression of AR, CYP17A1 and HSD3B2 was visualised using a peroxidase-conjugated avidin-biotin complex (60 min; Vector Laboratories) and 3,3-diaminobenzidine tetrahydrochloride (5 $\mathrm{min}$ in the dark; Zymed Laboratories, Cambridge, UK), while VASA was visualised by 3-amino-9-ethyl carbazol substrate chromogen (K3464, DAKO). Negative controls were carried out by omission of primary antibodies. After labelling, images of the full ovary (central section) were generated and all follicles and/or germ cells were counted, classified (as primordial, transitional or primary follicles) and identified for the presence of positive staining using a DXM 1200 digital camera Nikon (at $60 \times$ magnification). Histological classification of oocytes and follicles was performed primarily by FVC who was blinded to treatment procedure, i.e. whether sections were taken from PAtreated or control animals. Verification of the results in random sections was undertaken by an RA in the laboratory, who was also experienced in histological assessment of ovarian follicles.

\section{Quantitative PCR}

cDNA was prepared from mRNA extracted from whole ovary from five controls and six PA foetal sheep after treatment with DNAse I and SuperScript II reverse transcriptase (both from Invitrogen Life Technologies), according to the manufacturer's instructions and employed in a series of quantitative PCR (qPCR) studies. qPCRs were performed using KAPASYBR FAST Master Mix $(2 \times)$ ABI Prism (Kapabiosystems, Wilmington, MA, USA) and analysed by StepONe Plus Real-Time PCR System (Applied Biosystems). Details of the primers used are

Published by Bioscientifica Ltd 
Table 1 Primers used in the experiments

\begin{tabular}{lll} 
Target & & \multicolumn{1}{c}{ Accession number } \\
\cline { 1 - 1 } AR & & AF105713 \\
CYP17A1 & & NM_001009483 \\
HSD3B2 & & NM_001135932 \\
RPL19 & & NM_001112820 \\
\hline
\end{tabular}

\begin{tabular}{l} 
Forward sequence $\left(5^{\prime}-3^{\prime}\right)$ \\
\hline TATTGAAGGCTATGAGTGTCAGC \\
GGAGGTTCTGAGCAAGGAAGT \\
CTGCTGGAAGGAGACATTCTG \\
AATGCCAATGCCAACTC
\end{tabular}

Reward sequence $\left(3^{\prime}-5^{\prime}\right)$
GAAAGGAGTCAGGTTGGTTGTTGT
CAGCAAGTTAGTGATGGAGTCG
CTCTATGGTGCTGGTGTGGATA
CCCTTTCGCTACCTATACC

Species

Ovis aries

Ovis aries

Ovis aries

Ovis aries provided in Table 1 . We used the $2-\Delta \Delta \mathrm{Cq}$ (Livak) method to quantify relative gene expression (Schmittgen \& Livak 2008) and ran standard curves (to confirm 90-100\% efficiency). Annealing temperatures used were $56.4^{\circ} \mathrm{C}$ for CYP17A1 and AR, $59{ }^{\circ} \mathrm{C}$ for RPL19 and HSD3B2 (Table 1).

\section{Statistical analysis}

Where appropriate, data were stored in Microsoft Excel files. Statistical analysis of the effect of treatment on the proportion of growing follicles was carried out using Stata 10 for Macintosh (Stata Corporation, College Station, TX, USA), using logistic regression (logit command) for comparison of proportions of follicles, with CIs being computed using the Huber-White estimator of variance, adjusted to allow for clustering by sheep, as implemented in STATA using the 'cluster' option' (http://www.ats.ucla. edu/stat/stata/webbooks/reg/chapter4/statareg4.htm). This takes account of possible within-sheep correlation in follicle development. We have previously published the rationale for using this approach for analysis of human ovarian samples (Webber et al. 2003, 2007, Stubbs et al. 2007). Also using Stata 10, mean proportions of follicles at each stage of development, which were positive for AR or
$3 \beta \mathrm{HSD}$ (with one or more positive granulosa cells (GCs)) in control and androgenised, sheep were therefore computed and compared using logistic regression (clustered by sheep). Mean proportions of AR- or 3 $3 \mathrm{HSD}$-positive GCs at each stage of development were computed and compared using binomial regression (binreg command), (clustered by sheep). $P$ values were corrected for multiple comparisons at each stage of follicle development using the Bonferroni correction. In all cases, a probability value $(P)$ of $<0.05$ was considered to be statistically significant.

\section{Results}

\section{Follicle formation in PA foetal sheep ovaries at day 90 of gestation}

Immunolocalisation of VASA, a specific marker of germ cells, was used to distinguish the proportions of germ cells that were enclosed in follicles. As expected, VASA staining was localised to the cytoplasmic area of germ cells (Fig. 1A, B and C). Overall, 7246 germ cells and 1969 follicles were analysed: 2541 germ cells and 897 follicles in ovaries of PA sheep, and 4699 germ cells and 1005 follicles in ovaries of control sheep (Table 2).
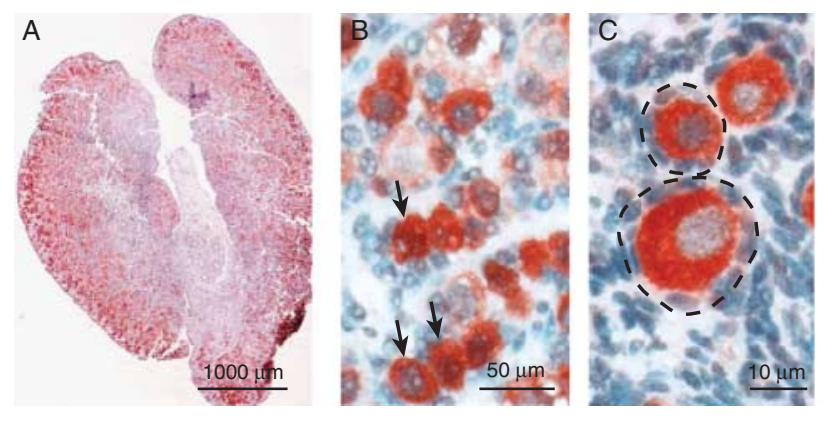

Figure 1

Germ cells in the foetal sheep ovary at day 90 of gestation. Germ cells were identified using VASA antibody and demonstrated $(A)$ at low power in hemisections of ovary and (B) at high power in foetal sheep ovary. Germ cells outside (arrow) (B) and within (C) follicles (dotted line showing outline) are illustrated. The proportions of germ cells within follicles are
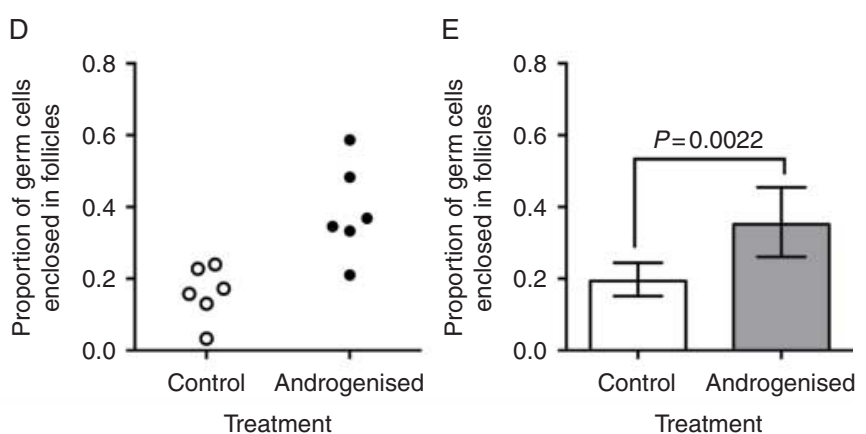

shown in (D) (individual animals) and (E) (error bars indicate $95 \% \mathrm{Cls}$ ). The proportion of enclosed germ cells was significantly higher in ovaries from prenatally androgenised (PA) animals than in controls ( ${ }^{*} P=0.002$, STATA, logistic regression clustered by sheep).

Published by Bioscientifica Ltd 
Table 2 Foetal sheep ovaries: numbers of follicles (granulosa cells) in the VASA study, and follicles (positive/total granulosa cells) in AR and in 3BHSD2 immunolabelling, organized by follicular stages

\begin{tabular}{|c|c|c|c|c|c|c|c|c|c|}
\hline & \multicolumn{3}{|c|}{ VASA } & \multicolumn{3}{|c|}{ AR } & \multicolumn{3}{|c|}{ HSD3B2 } \\
\hline & $\mathrm{P}$ & $\mathrm{T}$ & $1^{\text {ary }}$ & $P$ & $\mathrm{~T}$ & $1^{\text {ary }}$ & $P$ & $\mathrm{~T}$ & $1^{\text {ary }}$ \\
\hline Control $(n=6)$ & $\begin{array}{l}383 \\
(1601)\end{array}$ & $\begin{array}{l}537 \\
(3860)\end{array}$ & $\begin{array}{l}76 \\
(922)\end{array}$ & $\begin{array}{c}50 \\
(140 / 203)\end{array}$ & $\begin{array}{c}169 \\
(993 / 1177)\end{array}$ & $\begin{array}{c}44 \\
(416 / 496)\end{array}$ & $\begin{array}{c}179 \\
(320 / 784)\end{array}$ & $\begin{array}{c}220 \\
(861 / 1424)\end{array}$ & $\begin{array}{c}51 \\
(357 / 452)\end{array}$ \\
\hline $\begin{array}{l}\text { Androgenised } \\
\qquad(n=6)\end{array}$ & $\begin{array}{l}243 \\
(1244)\end{array}$ & $\begin{array}{l}562 \\
(3998)\end{array}$ & $\begin{array}{l}91 \\
(1130)\end{array}$ & $\begin{array}{c}71 \\
(257 / 315)\end{array}$ & $\begin{array}{c}175 \\
(1026 / 1196)\end{array}$ & $\begin{array}{c}58 \\
(595 / 645)\end{array}$ & $\begin{array}{c}94 \\
(262 / 419)\end{array}$ & $\begin{array}{c}187 \\
(1116 / 1372)\end{array}$ & $\begin{array}{c}92 \\
(711 / 822)\end{array}$ \\
\hline
\end{tabular}

P, primordial follicles; T, transitional follicles; $1^{\text {ary }}$, primary follicles.

The proportion of germ cells enclosed in follicles was significantly increased in PA sheep foetal ovaries when compared with normal sheep ovaries at day 90. As can be seen in Fig. 1D and E, PA sheep had nearly double the proportion of primordial follicles related to germ cells $(P=0.0022)$ (Table 2).

\section{Follicle activation in PA foetal sheep ovaries}

We examined the proportion of follicles at the primordial and early growing preantral stages (transitional and primary) in PA and control animals (Fig. 2). The difference between PA animals and controls was not significant.

\section{AR expression}

The presence of AR in samples of whole-ovarian tissue ( $n=5$ animals for controls, $n=6$ for PA) was evaluated by qPCR and in fixed and prepared ovarian sections by IHC (see Supplementary Table 2). In total, 567 follicles (263 in controls and 304 in androgenised sheep) and 4032 granulosa cells (1878 in controls and 2154 in androgenised sheep) were analysed in IHC studies.

Immunolabelling for AR protein was abundant in granulosa cells and stromal cells in the foetal ovary sections at day 90 of gestation (Fig. 3A), but a significantly higher proportion of follicles at the primordial primary stage expressed AR protein in androgenised animals compared with controls $(P<0.0001$, STATA, using the 'cluster' option). The effect of both follicle stage and treatment was analysed using logistic regression (logit command) (Fig. 4A). Moreover, when assessing the proportion of AR-positive GCs, a higher proportion of GCs (clustered by animal) in primordial and primary follicles from PA ovaries were AR-positive compared with ovaries from controls. In control animals, but not PA animals, there was also a stage-related increase in the proportion of GCs expressing AR protein (Fig. 4B).
There was, however, no significant difference between PA and control animals in the expression of mRNA for $\mathrm{AR}$, as measured by qPCR in tissue prepared from wholefoetal ovary.

\section{HSD3B2I and CYP17A1 expression}

HSD3B2 (3ßHSD2) protein expression was mainly confined to GCs, but was also observed in the interstitial stroma (Fig. 3B). When the proportion of follicles positive for HSD3B2 protein was analysed according to follicle stage, the proportion of follicles staining positive for HSD3B2 was higher at both the primordial $(P=0.0006)$ and transitional stages $(P=0.0006)$ in androgenised sheep compared with control sheep (Fig. 5A). The proportion of GCs staining positive for HSD3B2 was also higher at primordial $(P=0.0024)$ and transitional stages $(P=0.0135)$

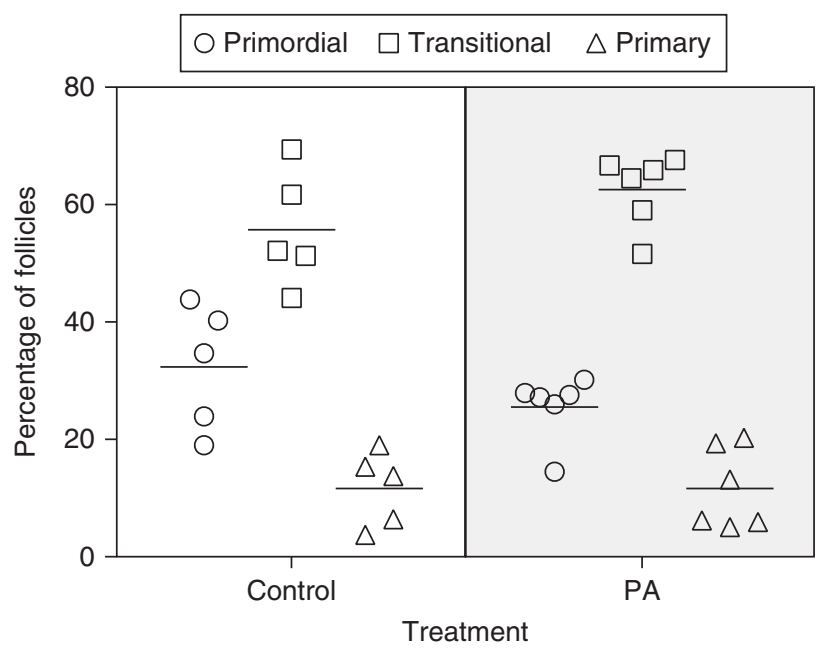

Figure 2

Proportion of primordial and growing follicles in the foetal sheep ovary. There was no effect of prenatal androgenisation on the proportion of primordial follicles (logistic regression, clustered by sheep, STATA.

Proportions are shown for individual animals for each follicle stage). 

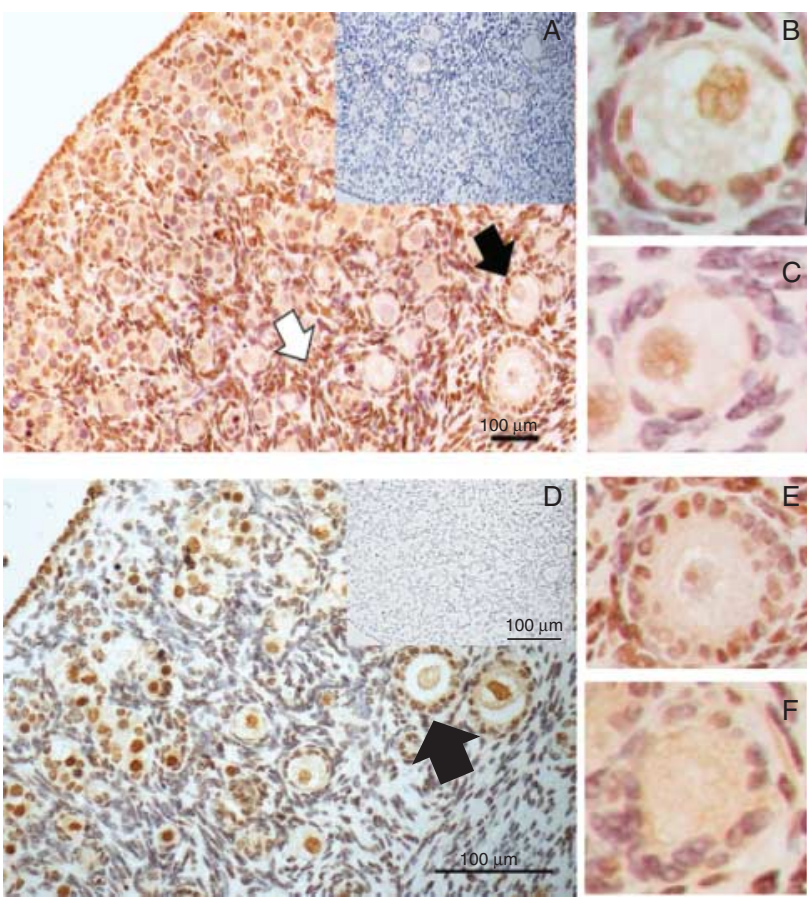

Figure 3

AR and HSD3B2 protein expression in foetal sheep ovary. (A) Positive staining for AR was identified mainly in stromal cells (white arrow) and, to a lesser extent, in granulosa cells (black arrow). The negative control is shown in the inset. Larger images of a follicle staining positively (B) or negatively for $A R$ (C) are shown. Positive staining for 3BHSD2 (3BHSD2) was identified mainly in granulosa cells from growing follicles (D) (black arrow); minimal labelling was demonstrated in the stroma; negative control is shown in the insert. Larger images of positively (E) and negatively stained follicles (F) are shown.

in androgenised sheep compared with controls, clustered by animal (Fig. 5B). Gene expression for HSD3B2 was, however, not significantly different between controls $(n=5)$ and androgenised sheep $(n=6)$ (PA sheep: fold change 0.97 (0.64-1.46) vs control sheep: 0.97 (0.75-1.35), (median, IQR)). In control animals, there was stage-related increase in the proportion of follicles (Fig. 5A) and GCs (Fig. 5B) expressing HSD3B2. Maternal exposure to androgens was associated with a reduction in the CYP17A1 gene expression in foetal sheep ovary at day 90 (PA sheep: fold change $0.43(0.30-0.72)$ vs control sheep: 1.5 (0.72-2.22) $(n=5)$, (median, IQR); $P=0.0004$, Mann Whitney). Protein expression of CYP17A1 was barely detectable by IHC in these studies and therefore not quantifiable (data not shown).

\section{Discussion}

The most important findings of this study were the differences between PA and control sheep in i) enhanced follicle formation and ii) altered expression of AR and steroidogenic enzymes in the foetal ovary. These findings largely support those of previously published work in the foetal sheep but differ from these studies importantly in terms of effects on timing of follicle formation and in activation and development of preantral follicles.

Evidence for advancement in the timing of follicle formation has previously been suggested by Smith and
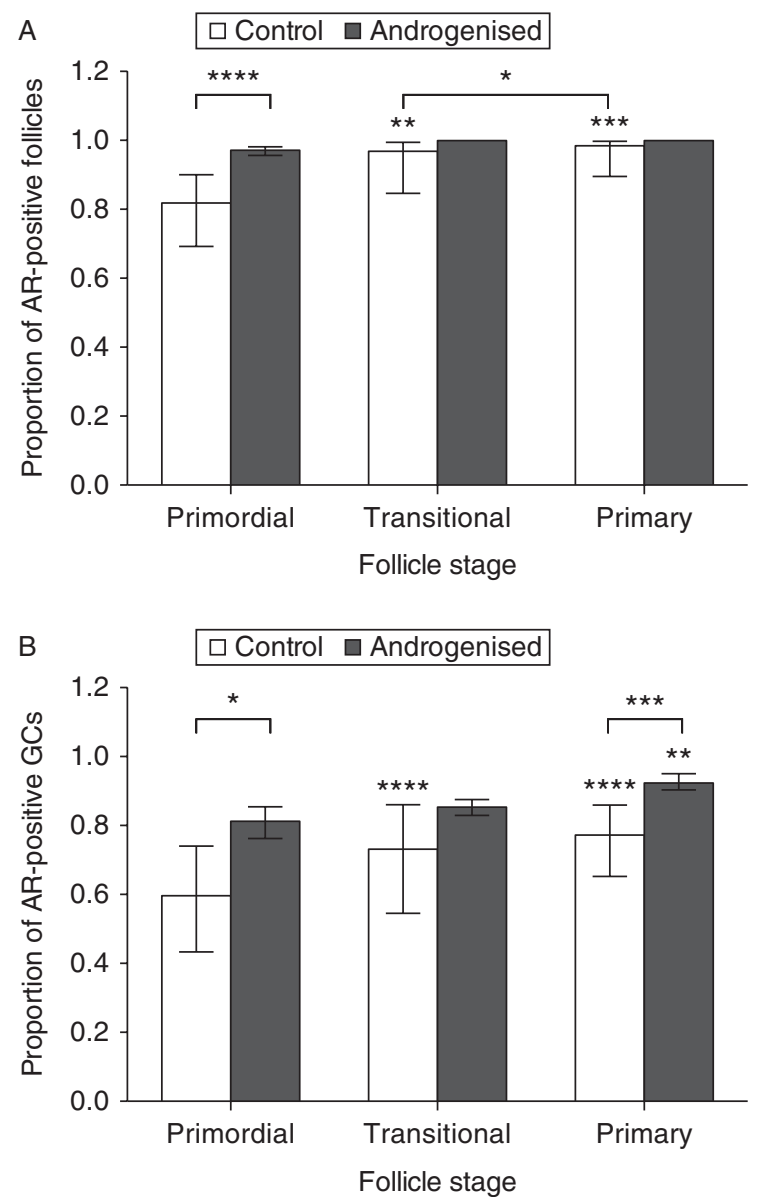

Figure 4

AR protein expression in follicles and GCs in foetal sheep ovary. (A) AR protein was expressed in a higher proportion of primordial follicles $(P<0.00001)$. In control follicles, the proportion of AR-positive follicles increased with follicle development, and was higher at the transitional $(P=0.001)$ and primary $(P=0.002)$ stages compared with primordial follicles. (B) The proportion of GCs expressing AR protein was significantly higher in PA animals at the primordial and primary stages, compared with those from control animals. In control animals, the proportion of ARpositive GCs increased with follicle development. Asterisks over error bars represent significant differences compared with the primordial stage. Data were analysed using logistic regression, clustered by animal (STATA); ${ }^{*} P<0.05, * * P<0.01, * * * P<0.001$ and $* * * * P \leq 0.0001$. Values are means and $95 \% \mathrm{Cl}$.

Published by Bioscientifica Ltd. 

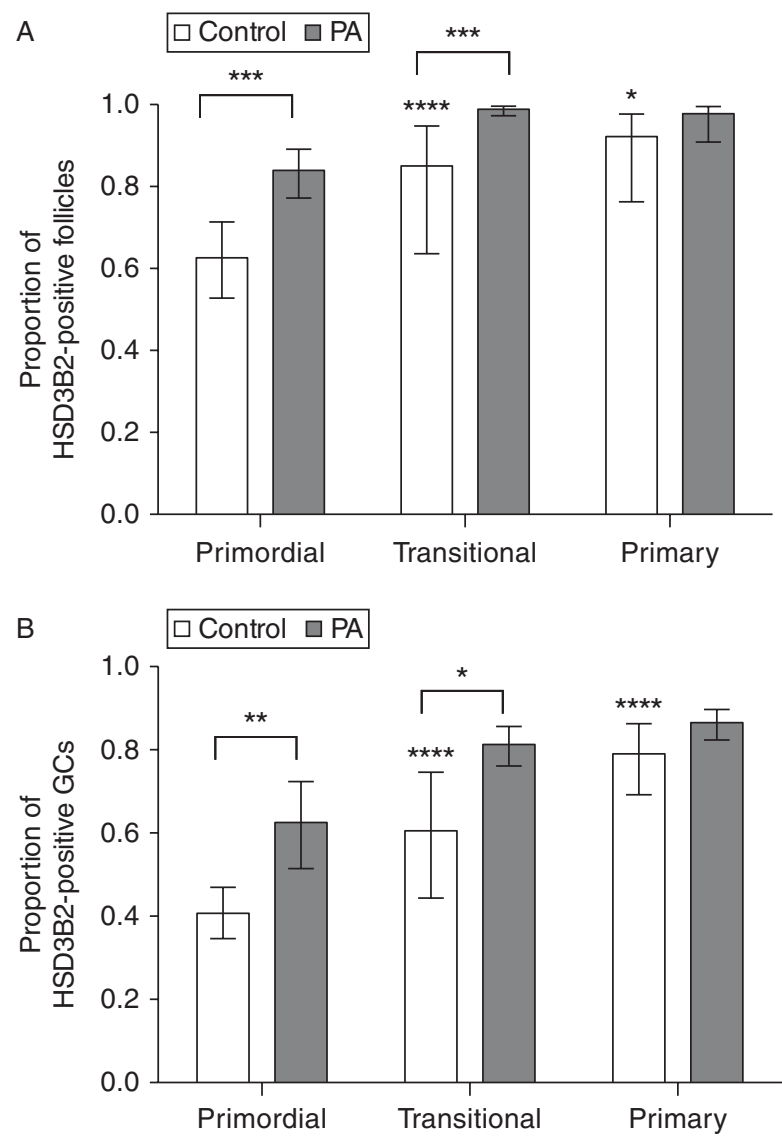

Figure 5

Expression of 3BHSD2 protein in foetal sheep ovary. The proportions of follicles (A) and of granulosa cells (B) immunolabelled for 3BHSD2 were significantly increased at both primordial and transitional stages in follicles of PA compared with control ovaries. ${ }^{*} P<0.05,{ }^{* * P} P 0.01, * * * P<0.001$ and $* * * * P<0.00001$ (STATA).

colleagues (Smith et al. 2009), although in those studies the difference (in total follicle number) between PA and control animals was observed at 140 days gestation rather than at 90 days. Neither testosterone nor DHT affected the total number of germ cells in the foetal ovary, but these investigators did not examine the proportion of germ cells enclosed in primordial follicles in the above-mentioned study. The two studies are therefore not directly comparable, not simply in terms of results but also taking into account the differences in breed of sheep and methodology. In this study, we used sections from core biopsies labelled with VASA (a very specific marker for germ cells), whereas Smith et al., used stereological analysis of $\mathrm{H}$ and $\mathrm{E}$ tissue. In addition, our classification of follicle stages included transitional follicles (type 1a; intermediate between primordial and primary) as growing follicles, a stage not included in the previous study.

With regard to follicle activation, we found no significant difference between PA and controls. These observations are in contrast to the findings of Smith et al. (2009) who found an increased proportion of growing follicles in both PA foetal sheep ovaries in late gestation and in adult offspring of PA animals. In their study, Smith et al. (2009) found differences between the effects of testosterone and dihydrotestosterone on follicle development. Specifically, they observed that activation of primordial follicles was increased significantly in testosterone-treated animals but less so in DHT-treated animals. They therefore suggested that the effect of testosterone on activation of follicle growth was mediated by conversion to oestradiol. This is plausible given that both placenta and possibly foetal ovary have the capacity to convert testosterone to oestradiol by the action of aromatase. However, in these studies, the doses of testosterone given are in excess of the capacity of placental aromatase to generate oestradiol so that the net effect is nevertheless predominantly androgenic (for example the external genitalia become masculinised) (Padmanabhan \& Veiga-Lopez 2011).

We observed increased expression of AR protein (but not in mRNA) in the follicles and granulosa cells of PA sheep ovary. These results are consistent with those of a previous study by Ortega et al., which reported enhanced protein expression of AR in the foetal ovary of Suffolk sheep, in that case detected by optical density (Ortega et al. 2009). The inability to detect differences in $A R$ mRNA levels between PA and control ovaries is consistent with the findings of Hogg et al. (2011) in Scottish Greyface sheep. This disparity between $A R$ gene and AR protein expression may reflect the lack of cell specificity of assessing gene expression from RNA prepared from whole ovary. However, it is well recognised that the abundance of protein does not necessarily correspond to the levels of mRNA (Maier et al. 2009, Vogel \& Marcotte 2012). It is plausible that androgenisation has differential effects on gene transcription, translation and protein stability.

Another example of discordant gene and protein expression can be seen in the finding of an increased proportion of HSD3B2 protein-positive follicles (and GCs) in PA sheep ovaries whilst gene expression for HSD3B2 was not affected. If increased HSD3B2 protein expression is associated with increased activity of the enzyme in granulosa cells, it would imply a shift from the delta-5 to

Published by Bioscientifica Ltd 
the delta-4 pathway of steroid biosynthesis in PA ovaries. Perhaps surprisingly, gene expression of CYP17A1 appears to be suppressed by excess testosterone, but the decrease in gene expression of CYP17A1 observed in our samples that echoes the findings of a recent report of Hogg et al. (2011) in which not only CYP17A1 but also STAR and CYP11A1 expression was reduced in the PA foetal ovary. Once again, changes in mRNA may not correspond to protein levels or activity but, in our study, CYP17A1 protein expression was too low to allow accurate morphometric quantification.

The differences between PA and control animals in the timing and/or extent of follicle formation also raise the question of the possible effects of prenatal exposure to androgen on the balance between cell proliferation and cell death. In a recent paper, Salvetti et al. (2012) has shown that BCL2 (an anti-apoptotic factor) is decreased in PA ovaries at day 90 (only) while other important mediators of proliferation and apoptosis (such as PCNA, caspase-3, FAS-ligand and BAX) were minimally affected.

In summary, the results of this study of Poll Dorset sheep indicate clearly that in foetal PA ovaries at day 90 of gestation there is a concomitant increase in $\mathrm{AR}$ protein expression in granulosa cells and important changes in both follicle formation and steroidogenesis. Given that there is an increase, compared with controls, in the density of preantral follicles in tissue from women with polycystic ovaries (Webber et al. 2003, 2007, Stubbs et al. 2007), these findings support the concept that aberrant follicle development in PCOS is programmed by exposure of the ovary to excess androgen during foetal life.

\section{Declaration of interest}

The authors declare that there is no conflict of interest that could be perceived as prejudicing the impartiality of the research reported.

\section{Funding}

This study was supported by the Medical Research Council (MRC Programme Grant G0802782). F V C was supported by Capes Foundation (Brazilian Ministry of Education).

\section{Author contribution statement}

F V C performed all the laboratory studies, made the initial analysis of the data and wrote the first drafts of the paper; J R was instrumental in setting up and managing androgen treatment, monitoring and surgery in the sheep; $\mathrm{KH}$ and S F conceived and supervised the project, analysed data and finalised the writing of the manuscript.

\section{Acknowledgements}

The authors would like to express their gratitude for the antibody samples generously given by Dr T Noce, Mitsubishi Kagaku from the Institute from Life Sciences, Japan (VASA antibody), Prof. J I Mason from the Edinburgh University, UK (3BHSDII antibody), Dr Richard Parker Jr, University of Alabama at Birmingham, USA (CYP17A1).

\section{References}

Abbott DH, Dumesic DA \& Franks S 2002 Developmental origin of polycystic ovary syndrome - a hypothesis. Journal of Endocrinology $\mathbf{1 7 4}$ 1-5. (doi:10.1677/joe.0.1740001)

Diamanti-Kandarakis E, Kouli CR, Bergiele AT, Filandra FA, Tsianateli TC, Spina GG, Zapanti ED \& Bartzis MI 1999 A survey of the polycystic ovary syndrome in the Greek island of Lesbos: hormonal and metabolic profile. Journal of Clinical Endocrinology and Metabolism 84 4006-4011. (doi:10.1210/jcem.84.11.6148)

Forsdike RA, Hardy K, Bull L, Stark J, Webber LJ, Stubbs S, Robinson JE \& Franks S 2007 Disordered follicle development in ovaries of prenatally androgenized ewes. Journal of Endocrinology 192 421-428. (doi:10.1677/ joe.1.07097)

Franks S 1995 Polycystic ovary syndrome. New England Journal of Medicine 333 853-861. (doi:10.1056/NEJM199509283331307)

Hogg K, McNeilly AS \& Duncan WC 2011 Prenatal androgen exposure leads to alterations in gene and protein expression in the ovine fetal ovary. Endocrinology 152 2048-2059. (doi:10.1210/en.2010-1219)

Maier T, Guell M \& Serrano L 2009 Correlation of mRNA and protein in complex biological samples. FEBS Letters 583 3966-3973. (doi:10.1016/ j.febslet.2009.10.036)

Ortega HH, Salvetti NR \& Padmanabhan V 2009 Developmental programming: prenatal androgen excess disrupts ovarian steroid receptor balance. Reproduction 137 865-877. (doi:10.1530/REP-080491)

Padmanabhan V \& Veiga-Lopez A 2011 Developmental origin of reproductive and metabolic dysfunctions: androgenic versus estrogenic reprogramming. Seminars in Reproductive Medicine 29 173-186. (doi:10.1055/s-0031-1275519)

Padmanabhan V \& Veiga-Lopez A 2013 Sheep models of polycystic ovary syndrome phenotype. Molecular and Cellular Endocrinology 373 8-20. (doi:10.1016/j.mce.2012.10.005)

Salvetti NR, Ortega HH, Veiga-Lopez A \& Padmanabhan V 2012 Developmental programming: impact of prenatal testosterone excess on ovarian cell proliferation and apoptotic factors in sheep. Biology of Reproduction 87 22, 1-10. (doi:10.1095/biolreprod.112.100024)

Schmittgen TD \& Livak KJ 2008 Analyzing real-time PCR data by the comparative C(T) method. Nature Protocols 3 1101-1108. (doi:10.1038/ nprot.2008.73)

Sharma TP, Herkimer C, West C, Ye W, Birch R, Robinson JE, Foster DL \& Padmanabhan V 2002 Fetal programming: prenatal androgen disrupts positive feedback actions of estradiol but does not affect timing of puberty in female sheep. Biology of Reproduction 66 924-933. (doi:10.1095/biolreprod66.4.924)

Smith P, Steckler TL, Veiga-Lopez A \& Padmanabhan V 2009 Developmental programming: differential effects of prenatal testosterone and dihydrotestosterone on follicular recruitment, depletion of follicular reserve, and ovarian morphology in sheep. Biology of Reproduction $\mathbf{8 0}$ 726-736. (doi:10.1095/biolreprod.108.072801)

Stubbs SA, Hardy K, Da Silva-Buttkus P, Stark J, Webber LJ, Flanagan AM, Themmen AP, Visser JA, Groome NP \& Franks S 2005 Anti-mullerian hormone protein expression is reduced during the initial stages of follicle development in human polycystic ovaries. Journal of Clinical Endocrinology and Metabolism 90 5536-5543. (doi:10.1210/jc.20050907)

Published by Bioscientifica Ltd. 
Stubbs SA, Stark J, Dilworth SM, Franks S \& Hardy K 2007 Abnormal preantral folliculogenesis in polycystic ovaries is associated with increased granulosa cell division. Journal of Clinical Endocrinology and Metabolism 92 4418-4426. (doi:10.1210/jc.2007-0729)

Vogel C \& Marcotte EM 2012 Insights into the regulation of protein abundance from proteomic and transcriptomic analyses. Nature Reviews. Genetics 13 227-232. (doi:10.1038/nrg3185)
Webber LJ, Stubbs S, Stark J, Trew GH, Margara R, Hardy K \& Franks S 2003 Formation and early development of follicles in the polycystic ovary. Lancet 362 1017-1021. (doi:10.1016/S0140-6736(03)14410-8)

Webber LJ, Stubbs SA, Stark J, Margara RA, Trew GH, Lavery SA, Hardy K \& Franks S 2007 Prolonged survival in culture of preantral follicles from polycystic ovaries. Journal of Clinical Endocrinology and Metabolism 92 1975-1978. (doi:10.1210/jc.2006-1422)

Received in final form 22 January 2015

Accepted 13 February 2015
Published by Bioscientifica Ltd. 